sie sich vom Rücken her zur Gegenpalpation bringen. Die linke Beckenschaufel ist von dem Tumor ganz ausgefüllt. Die rechte Beckenschaufel und die Mittellinie, letztere 2 Finger hoch über der Symphyse, zeigen tympanitischen Schall. Ueber dem Tumor absolute Dämpfung. Untere Grenze der absolnten Leberdämpfung in der Parasternallinie im sechsten, in der Mamillarlinie im 7. Intercostalraume.

Aufblasung vom Mastdarm aus zeigt dem Auge dentlich, dass das Colon descendens über die Vorderfläche der Geschwulst verlänft.

Bei rechter Seitenlage sinkt der Tumor nur wenig nach rechts, linke Beckenschaufel und Lumbalgegend bleiben dabei völlig gedämpft. In Rückenlage ist die Geschwulst mässig von rechts nach links, etwas nach abwärts, ziemlich stark nach aufwärts verschieblich. Bei seitlicher Verschiebung weicht sie stark nach links aus, so dass er in der Lendengegend eine grobe Hervorwölbung bildet.

Oberfläche der Geschwulst glatt, Consistenz prall elastisch. Hymen non perforatum.

Rectaluntersuchung: Uterus dextroponirt, anteflectirt und frei beweglich. Ovarien nicht zu tasten. Kein Tumorabschnitt im Becken zu fühlen.

Diagnose: Nierentumor, wahrscheinlich Hydronephrose.

Der Operationsverlauf ist oben geschildert. Von dem Verlanfe der Nachbehandlung ist bemerkenswerth, dass Störungen der Urinabsonderung nicht bestanden; die Harnmenge betrug vom Tage post operationem an 1000 und mehr. Allein bei reizlosem Wundverlaufe trat am Tage nach der Operation eine Temperatursteigerung bis $39^{\circ}$ ein, welche Temperatur auch noch am nächsten Tage erreicht wurde; dabei wurden mehrfach diarrhoeische Stühle entleert. Der locale Verlauf und das Allgemeinbefinden waren so gut, dass am 2. Tage schon ein Theil des Tampons, am vierten sein Rest entfernt werden konnte. Die Temperatur sank langsam, um erst am 9. Tage die Norm zu erreichen. Ohne Secretion trat ganz glatt die Heilung ein. Eine ähnliche Temperatursteigerung trat am 3. und 4. Tage nach der 2. Operation ein, ebenfalls von diarrhoeischen Stühlen begleitet.

\title{
4.
}

\section{Carcinom des Halses der Gallenblase von der Grösse eines Kirschsteines.}

Fon

Prof. L. Heidenhain.

Vor einem Jahre habe ich in der deutschen medicinischen Wochenschrift ${ }^{1}$ ) über die Exstirpation einer krebsigen Gallenblase mit Resection eines nicht kleinen Stückes Leber berichtet. Vor der Operation hatte ich den von einem Collegen geäusserten Verdacht eines Krebses der Gallenblase abgelehnt und die wahrnehmbaren Ungleichheiten der Oberfläche des Gallenblasentumors auf Netzadhärenzen bezogen. Solche fanden sich

1) 1897. Nr. 4. 
in der That und gaben die ausreichende Erklärung für den Palpationsbefund. Daneben fand sich bei Spaltung der Gallenblase zu meinem grössten Erstaunen ein noch rein intramural gelagertes, von der Schleimhaut ausgegangenes Carcinom der Gallenblase. Die Leber erschien makroskopisch noch gesund. Trotzdem ist die Kranke sehr bald nach Heilung der Operationswunde an Lebermetastasen zu Grunde gegangen. Am Präparate liess sich deutlich nachweisen, dass die krebsige Entartung der Gallenblasenschleimhaut von der Stelle ausgegangen war, an welcher offenbar seit Jahren ein grosser Gallenstein gelegen hatte. Vor einigen Wochen bin ich rein zufällig bei einer Operation wegen Gallensteinen wieder auf ein Carcinom der Gallenblase, diesnual im ersten Beginne, Kirschsteingrösse, gestossen. Ich sah die 60 jährige Kranke zuerst Anfang August 1897 mit einem typischen Gallenblasentumor und den Zeichen der Eiterung in der Gallenblase. Leider verschob die Kranke aus äusseren Gründen den Eingriff um einige Wochen. Sie kam dann am 9. Septbr. zur Operation mit einem perforirenden Gallenblasenempyem, Abscess zwischen Gallenblase, adhärenten Dünndärmen und Bauchwand. Den Abscess habe ich zunächst eröffnet und abgewartet, bis die Eiterung einen mehr schleimigen Charakter, angenommen und die sehr elende Kranke sich erholt hatte. Da durch die Fistel sich keine Steine entleerten, auch mit Laminariadilatation nicht an die Steine heranzukommen war, so liess ich am 11. November 1897 die Radicaloperation folgen. Durch massige, enorm feste Adhäsionen war die Freilegung der Gallenblase recht schwierig. Sie war klein, geschrumpft und enthielt neben einigen ganz kleinen sechs Steinen mittlerer Grösse. Nach Entleerung dieser floss keine Galle ab. Sondiren liess sich der Cysticus nicht; von aussen liess sich auch nicht feststellen, ob eine Obliteration des Ductus oder nur eine Schleimhautschwellung vorliege, welche der Galle den Abfluss versperrte. Eine Schleimfistel wollte ich in keinem Falle zurücklassen, auch konnte ja das Hinderniss für den Gallenabfluss ein weiterer Stein sein; darum spaltete ich die Blase so weit, dass man ihr Inneres völlig übersehen konnte. Es zeigte sich nun am Gallenblasenhalse, dicht am Uebergange in den Cysticus, eine knopfförmige Prominenz auf der Schleimhaut von der Grösse etwa eines Kirschensteines. Deren Oberfläche war anscheinend nicht ulcerirt, allein sie erschien mir doch so verdächtig, dass ich die Gallenblase exstirpirte in der Befürchtung, es mit einem Carcinom zu thun zu haben. Um den Cysticus ganz mit entfernen zu können, habe ich die einfache Excision des Cysticus aus der Wand des Choledochus gemacht ohne den Gallenblasengang za unterbinden. Aus dem Choledochus floss Galle. Mit nur einer Naht habe ich das Loch in der Wand desselben übernähen können und dann ein umwickeltes Drain auf das Loch geführt. Der obere Theil der Wunde wurde tamponirt, der untere genäht. - Die Leber zeigte bei der Operation normale Grösse und normales Aussehen.

Der locale Wundverlauf war glatt, das heisst es kam ohne nennenswerthe Eiterung zu guter Granulation. Indessen trat am 3. Tage eine trockene Pericarditis mit ziemlicher Pulsschwäche ein, welche mir einige Tage lang Sorgen machte. Doch ging sie schnell und, so weit ich finden konnte, spurlos vorüber. Die Genese der Herzbeutelentzündung ist mir unklar geblieben. Als Metastase kann man sie nicht gut auffassen, da 
Wundeiterung nicht bestand (auch Galle ist nie aus der Wunde abgeflossen), und nirgends sonst am Körper Störungen sich fanden.

Bei der mikroskopischen Untersuchung des Präparates fand sich ein eben beginnender Krebs der Gallenblasenschleimhaut. Die Drüsen der Schleimhaut waren gewuchert und drangen in die Muscularis der Wandung ein. Oberflächlich bestand Ulceration. Der bösartige Charakter der Wucherung war dadurch sicher zu stellen, dass hier und da die Lymphgefässe in der Muscularis sich mit Epithelzellen a usgestopft fanden in derselben Weise, wie ich dies seiner Zeit beim Brustkrebse beschrieben habe. Neben der Neubildung fanden sich an 2 Stellen kleine Decubitusgeschwüre der Schleimhaut der Gallenblase.

Am 23. December 1897 wurde die Kranke mit linsengrosser, oberflächlicher Granulationsfläche aus dem Krankenhause in ihre Stadtwohnung entlassen; zu dieser Zeit schon verursachte mir eine mässige, doch deutlich palpabele Lebervergrösserung ohne Icterus Sorge. Jetzt Anfang Februar 1898 liegt Pat. mit einem Lebercarcinom, welches den Nabel ubberreicht, hoffnungslos darnieder. Es hat in diesem Falle ein ganz besonderer Zufall gewaltet. Ich habe den Hausarzt der Kranken nur dadurch zur Zustimmung zur Operation bewegen können, dass ich ihm sagte, man könne bei einer Frau in diesem Alter nie wissen, ob sich nicht in der Steinblase ein Krebs entwickele, denn Gallensteine seien die häufigste veranlassende Ursache zur Entstehung des Gallenblasenkrebses, und viele Frauen gingen an diesem Leiden zu Grunde. Gerade in diesem Falle hat sich ein Krebs in den ersten Stadien der Entwicklung vorgefunden, und dann der überschnelle Verlauf!

Was für Folgerungen soll man aus diesem merkwürdigen Falle ziehen? Meines Erachtens folgende:

1. Bei langdauernden Gallensteinleiden, welche trotz innerlicher Behandlung immer wiederkehren, soll man operiren; unbedingt muss operirt werden, wenn ein Gailenblasentumor über Wochen und Monate bestehen bleibt, der inneren Therapie zum Trotze.

2. Bei der Operation von Steinblasen soll man die Gallenblase so weit eröffnen, dass man ihr Inneres ganz überseheu kann, damit man nicht ein beginnendes Carcinom tibersieht. Ein etwas grösseres Loch wieder zuzunähen, ist ja kein Kunststück. ')

1) Auf die genauere Wiedergabe der Krankengeschichte glaube ich verzichten zu können. Sie gleicht genau den zahllosen Krankengeschichten, die über Gallen blasen mit Steinen schon veröffentlicht sind. 